\title{
SÍNDROME DE CAPGRAS
}

\author{
Fabiana Rodrigues Fagote, Isadora Pires Peres, Lucas Teodoro Strelau \\ Universidade do Oeste Paulista - UNOESTE, Faculdade de Medicina, Presidente Prudente, SP. E-mail: \\ fabiana fagote@hotmail.com
}

\section{RESUMO}

O Delírio de Capgras é a alteração psicopatológica mais relatada presente nas Síndromes Delirantes de Falsa Identificação. Nesta síndrome o paciente descreve que indivíduos intimamente relacionados com ele foram substituídos por duplos ou sósias, "homônimos", que assumem os papéis das pessoas que personificam e se comportam de maneira idêntica. Assim, o objetivo deste estudo é relatar um caso de delírio de Capgras com outras associações psicopatológicas. O caso em questão revela uma paciente com um conjunto de sinais e sintomas, como a esquizofrenia do tipo paranoide e transtorno de ansiedade, associados a um quadro de erro de identificação delirante caracterizado pela despersonificação de suas filhas, o que corrobora para fechar o diagnóstico de síndrome de Capgras. Conclui-se que esta síndrome pode ser subdiagnosticada nos serviços de saúde, devido a dificuldade em estabelecer um diagnóstico por se tratar de um sintoma associado a outra psicopatologia. Desta forma, torna-se importante o relato para a área médica, no intuito de acrescentar novas informações sobre esta síndrome considerada rara.

Palavras-chave: psiquiatria, psicopatologia, medicina, diagnóstico.

\section{CAPGRAS SYNDROME}

\section{ABSTRACT}

The Delirium of Capgras, the most reported of the Delirious Syndromes of False Identification. In this syndrome the patient describes that individuals closely related to him have been replaced by double or semia, "homonyms," who assume the roles of people who personify and behave identically. Thus, the objective of this study is to report a case of Capgras delirium with other psychopathological associations. The case in question reveals a patient with a set of signs and symptoms, such as paranoid schizophrenia and anxiety disorder, associated with a delusional identification error characterized by the depersonification of her daughters, which corroborates the diagnosis of Capgras syndrome. It is concluded that this syndrome may be underdiagnosed in the health services, due to the difficulty in establishing a diagnosis because it is a symptom associated with another psychopathology. Thus, it is important to report to the medical area, in order to add new information about this syndrome considered rare.

Keywords: psychiatry, psychopathology, medicine, diagnosis.

\section{INTRODUÇÃO}

O Delírio de Capgras, a mais relatada das Síndromes Delirantes de Falsa Identificação (SDFI), ocorre tanto em quadros esquizofrênicos, de humor e mentais orgânicos (distúrbios de identificação envolvendo locais são mais comuns em quadros orgânicos, ao passo que os distúrbios de identificação envolvendo o próprio paciente ou outras pessoas são mais vistos em quadros funcionais), cuja característica principal é um erro de identificação delirante de si próprio e/ou de outras pessoas. Neste processo, o paciente descreve que indivíduos intimamente relacionados com ele foram substituídos por duplos ou sósias, "homônimos", que assumem os 
papéis das pessoas que personificam e se comportam de maneira idêntica. ${ }^{1}$

Sugerem que a paramnésia reduplicativa e a prosopagnosia poderiam ser incluídos entre os distúrbios de identificação. $\mathrm{Na}$ primeira, o paciente acredita que situações do presente são réplicas de situações passadas, envolvendo lugares, pessoas e objetos. Á prosopagnosia é uma síndrome em que o paciente tem dificuldade de reconhecer rostos familiares, porém é capaz de identificar corretamente o sujeito através de outras características. É relatado que a prosopagnosia possa ser um fator predisponente ao desenvolvimento dos delírios de substituição, como o Delírio de Capgras. ${ }^{2}$

A Síndrome de Capgras, pode ser uma resposta psicótica a uma ambivalência intolerável ou a mudanças dos sentimentos afetivos e sentimentos de estranheza do paciente. Sendo tais sentimentos, a resolução destes pacientes é a ilusão de sósias e não alguma outra resposta, devido às experiências angustiantes de despersonalização e desrealização vivenciaram, que os levaria a projetar no mundo externo o seu sentimento de estranheza, atribuindo ao outro a qualidade de "homônimo" ou detentor da mudança.

Na síndrome de Capgras é possível propor disfunção do hemisfério cerebral direito em associação com lesões occiptoparietais, de acordo com teorias neuropsicodinâmicas, além de inferir uma disfunção da via de reconhecimento perceptual pré-consciente, entre o córtex visual e o sistema límbico, via parietal inferior. Sendo assim, ocorre dificuldade de interpretação, o sujeito reconheceria morfológica e semanticamente o percepto, mas sem a confirmação afetiva da informação.

Neste estudo objetiva-se apresentar um caso clínico de uma paciente, dona de casa, sem tratamento psiquiátrico prévio, com antecedentes familiares esquizofrênicos, mau relacionamento com os pais, quadro de depressão pós-parto, que desenvolveu delírios de substituição envolvendo suas filhas, alegando o uso de máscaras pelas mesmas, além de comportamentos anormais dos parentes. Assim, por meio deste relato é possível inferir que diferentes origens e etiologias contribuem para a gênese do Delírio de Capgras, que pode apresentar-se concomitantemente com outras manifestações psiquiátricas ou de forma isolada. ${ }^{3}$

\section{RELATO DE CASO}

O caso apresentado trata-se de um quadro psiquiátrico iniciado em idade acima dos 30 anos, marcado por atividade alucinatória relacionada com o conteúdo delirante místico e associada a síndromes de falsa identificação delirante.

K.C.F.S , 31 anos, parda, ensino médio incompleto, evangélica, solteira, dona de casa. Chegou ao hospital acompanhado de sua tia paterna com encaminhamento da Unidade Básica de Saúde (UBS) com diagnóstico de F41 (transtornos ansiosos). Reside em casa própria com as duas filhas, sendo uma de 5 e outra de 7 anos de idade. Nega histórico prévio de internações na Psiquiatria, tentativa ou gestos suicidas, problemas com a justiça e uso de medicamentos psiquiátricos.

Ao exame físico geral, apresentou um bom estado geral, sistemas cardiovascular, respiratório, gastrointestinal e neurológico sem alterações. Ao exame psíquico, encontrava-se no leito, calma, orientada, pensamento delirante místico, discurso coerente, referindo que não reconhece as filhas e acha que elas foram trocadas. Sem alteração de afeto.

Ao ser indagada pelo motivo de estar ali, ela relatou que na noite anterior começou a sentir uma dor muito forte no peito e pensou estar enfartando, foi então para a casa do pai, que com a ajuda da tia a levaram para o hospital.

Antes da internação, ela já havia trabalhado duas vezes, mas, devido a inúmeras faltas e um desentendimento com outra funcionária, acabou sendo demitida. A tia refere que após o parto da primeira filha, a paciente ficou cerca de 40 dias muito desorganizada e delirante. Já na gestação da segunda filha, desenvolveu depressão pós-parto, situação em que possuía sintomas depressivos com humor hipotímico. Então buscou ajuda e foi tratada com antidepressivo e ansiolítico, os quais não recorda o nome.

Ela nunca se deu bem com a mãe, tendo uma afinidade maior com a avó materna, a qual chama de mãe. A convivência com o pai sempre foi difícil, pelo fato de ser filha de um relacionamento extraconjugal, e a mãe sempre impedia a comunicação entre ambos. 0 relacionamento com as filhas sempre foi bom, embora familiares tenham relatado que nos últimos tempos a paciente estaria abdicando cuidados, por acreditar que aquelas não eram suas filhas de verdade, e sim sósias. Ela nos conta 
que ultimamente tem se assustado com alguns sonhos de sua filha mais nova.

A paciente apresentava isolamento social (não gostava de frequentar lugares com muitas pessoas) sendo seus únicos lazeres ir ao culto ou ao parque com as filhas. Sua rotina era sempre a mesma, e ela se sentia uma pessoa muito feliz.

Os sintomas se iniciaram com delírios místicos de características persecutórias e psicóticas há alguns meses. Segundo K., ela recebeu o Espírito Santo e somente ela sabia quem era Deus na verdade. Ela também acreditava que familiares estavam escondendo informações sobre outros membros da família, e que os primos estavam tentando se comunicar com ela através de propagandas televisivas.

Disse que realizou o velório da mãe e das irmãs, que ainda se encontram vivas. A tia descreve que começou a estranhar quando ela falou que iria mudar de casa, já que mora perto dos familiares, querendo se ver livre de todos para poder cuidar das filhas. Passou a não cumprimentar mais as pessoas, inclusive membros da própria família, e não permitia que as filhas cumprimentassem também. Andava muito angustiada, inquieta e apresentava risos imotivados ao se olhar no espelho.

Há relatos de que quatro dias antecedentes à internação iniciou com episódios de agorafobia (não caracterizando ataques de pânico), angústia, sensação de despersonalização, sudorese e principalmente passou a acreditar que por vezes suas filhas foram substituídas por outras crianças ou estavam de máscara.

A tia presenciou K. "abrindo os olhos" de suas filhas com o dedo e resmungando coisas do tipo "Tá vendo? Você está de máscara"- SIC, em outros momentos ficava pedindo para as meninas cantarem para comparar as suas vozes. K. disse que as filhas verdadeiras estão com problemas de saúde e foram internadas, e que aquelas eram pessoas de vida passada. Ainda nos informa que percebeu os primeiros sintomas após sua filha lhe contar algo que a entristeceu muito, mas não nos revelou o segredo.

Como antecedentes familiares possui 2 tias com diversos surtos psicóticos e internações prévias, avó paterna, materna, mãe e tia com diagnóstico de esquizofrenia.

A paciente ficou internada por um período de 16 dias. Seus exames laboratoriais não apresentaram nenhuma alteração. Teve uma boa evolução, apresentando-se calma, consciente, orientada e colaborativa durante todos os dias que esteve no hospital. Apresentou apenas um episódio de intercorrência onde questionou a conduta médica.

Para o tratamento e controle da sintomatologia a paciente recebeu o antipsicótico Risperidona, sendo necessário o ajuste de dose em até $6 \mathrm{mg} / \mathrm{dia}$, associado a Levomepromazina $4 \%$ na dose de 15 gotas diárias.

No momento da alta, evidenciava melhora, porém indagou à tia se ela se lembrava de uma irmã que havia falecido quando $\mathrm{K}$. ainda era criança, pois ela tinha certeza que sua verdadeira mãe era ela. Disse também que iria descobrir o que os familiares estavam escondendo dela e apresentava dispneia.

Apresentou como diagnóstico Esquizofrenia acrescido de Síndrome de Capgras evidenciando a dificuldade de diagnóstico clinico para tal psicopatologia, uma vez que a mesma está associada a outras comorbidades psiquiátricas.

Recebeu alta com guia de referência para continuidade do tratamento ambulatorial na rede municipal. Compareceu em duas consultas antes de abandonar o tratamento.

\section{DISCUSSÃO}

A mais comum de todas as síndromes de falsa identificação delirante é Capgras, ocorrendo em mais de $4 \%$ dos pacientes com psicose. Encontra-se estatisticamente associado com esquizofrenia de tipo paranóide, o que justifica a associação do quadro descrito com o diagnóstico de Esquizofrenia. Estudos atuais têm mostrado que entre 25 e $40 \%$ dos casos estão associados a distúrbios orgânicos. 4

O delírio de Capgras pode ser explicado por duas hipóteses de acordo com a literatura. A teoria psicodinâmica postula que a síndrome surge como uma forma de lidar com sentimentos ambivalentes face a um sujeito que lhe é próximo, geralmente "transferindo" os sentimentos de raiva para o "impostor" de forma a manter apenas sentimentos positivos face ao indivíduo querido. Já a teoria orgânica postula que apesar do indivíduo permanecer com a capacidade de identificação, existe uma lesão cerebral que interfere na capacidade do indivíduo em sentir familiaridade face a alguém que lhe é próximo.

Conforme história e exame clínicos, descarta-se a possibilidade de os sintomas psicóticos serem decorrentes de patologia orgânica, abuso de substâncias e/ou delirium. É 
notório atualmente a elevação progressiva dos casos de delírio de Capgras, e parece não existir predileção entre um dos sexos. ${ }^{3}$

Ao exame psíquico a paciente apresentava pensamento delirante místico, referindo que as filhas haviam sido substituídas por sósias. "Neste sentido, a síndrome de Capgras é a crença delirante de que uma pessoa foi substituída por outra ("um impostor"), que seria psicologicamente diferente, mas fisicamente idêntica ao substituído". ${ }^{1}$

Quando no contexto de um distúrbio psiquiátrico, o delírio parece ser mais insidioso e associado a sintomas psicóticos, frequentemente paranoides. Geralmente estes pacientes encaram o delírio como ameaçador, mantendo sentimentos hostis face ao suposto "impostor". Nestes pacientes a consistência da crença parece ser menor, podendo apresentar um padrão, como evidenciado no caso descrito. ${ }^{2}$

Os sintomas podem ter uma duração variada, sendo classificados como transitórios ou crônicos. No mesmo dia pode ocorrer uma flutuação com reconhecimento e depois retornar ao delírio. Situações de stress extremo ou recaídas psicóticas podem desencadear o delírio em alguns destes pacientes. ${ }^{3}$

Sabendo-se que a sintomatologia da paciente persistiu por alguns meses, evidencia-se uma permanência dos sintomas, o que contribui para uma piora do prognóstico.

Os antipsicóticos são divididos basicamente em dois grupos: antipsicóticos típicos e antipsicóticos atípicos. Os típicos ou convencionais são antagonistas dos receptores de dopamina e seu efeito é a redução dos sintomas positivos (delírio, alucinações e pensamento incoerente), porem são responsáveis por uma série de efeitos colaterais, principalmente os extrapiramidais. Os atípicos possuem maior afinidade por receptores serotoninérgicos do que por receptores dopaminérgicos. A ação antagonista serotoninérgica dos antipsicóticos atípicos diminui o aparecimento de sintomas extrapiramidais e sua menor afinidade pelos dopaminérgicos contribuem para este efeito.

A Risperidona, a qual pertence ao grupo de antipsicóticos-neurolépticos atípicos, foi a droga de escolha no tratamento da paciente devido a sua eficácia no controle da doença, tanto no momento do surto psicótico como na manutenção. Ela possui uma eficácia similar à dos antipsicóticos típicos, porém com menos efeitos colaterais. Além disto, já contamos hoje com a formulação de liberação prolongada injetável e que necessita de apenas uma aplicação a cada duas semanas, facilitando a adesão e permanência no tratamento, garantindo melhora de perspectiva de vida aos pacientes. ${ }^{5}$

\section{CONCLUSÃO}

O caso em questão revela que a paciente apresenta um conjunto de sinais e sintomas, como a esquizofrenia do tipo paranoide e transtorno de ansiedade, e associado a isto, um quadro de erro de identificação delirante caracterizado pela despersonificação de suas filhas, o que corrobora para fechar o diagnóstico de síndrome de Capgras.

Entende-se que um possível tratamento para a síndrome de Capgras, seja o fármaco Risperidona que aparece como droga de escolha devido aos baixos números de efeitos colaterais e neste mesmo contexto, surge a forma de ação prolongada, que devido a facilidade no uso, estimula a adesão ao tratamento por estes pacientes.

É possível inferir também que esta síndrome pode ser subdiagnosticada nos serviços de saúde, devido à dificuldade em se estabelecer um diagnóstico por se tratar de um sintoma associado a outra psicopatologia. Desta forma, torna-se importante o relato para a área médica, no intuito de acrescentar novas informações sobre esta síndrome considerada rara.

O estudo apresentou ainda algumas limitações, uma vez que não foi possível acompanhar a evolução da paciente após a alta e por último, a dificuldade em encontrar na literatura informações com bases cientificas sobre o tema, portanto, há necessidade de novos saberes que direcione a área medica para o tratamento adequado desta síndrome.

\section{REFERÊNCIAS}

1. Turkiewicz G., Zanetti MV, Zung S, Cordeiro Q. Coexistência das síndromes de Capgras e Frégoli associadas à redução de volume frontotemporal e hiperintensidades em substância branca cerebral. Psiquiatria Clínica, 2009;(36, Sppl 6): 240-243. $\quad$ https://doi.org/10.1590/S0101$\underline{60832009000600004}$

2. Silva LAP, Nicolato R. SíNDROME DE CAPGRAS: RELATO DE CASO E REVISÃO DE LITERATURA. Casos Clínicos de Psiquiatria, 2000; (2, Sppl 2): 62-65. 
3. Santos MCM. Abordagem e Etiologia do Síndrome de Capgras. Uma Revisão Sistemática. Ciências Biomédicas de Abel Salazar 2013; 1-27. Disponível em: https://repositorioaberto.up.pt/bitstream/10216/71783/2/93270.p df

4. Ferreira TS, Moreira T, Mendes M, Ferreira S. Síndromes de Falsa Identificação Delirante e Esquizofrenia Paranóide, a Propósito de um Caso Clínico. Serviço de Psiquiatria do Hospital Prof. doutor Fernando Fonseca, 2015 Dez; (13 Sppl 2): p.89-96.

5. Nunes LB, Christoff AO, Valle LL. AVALIAÇÃO DOS EFEITOS DA RISPERIDONA INJETÁVEL NA ESQUIZOFRENIA. Unibrasil, 2017; 1-17.

6. Silva RCB. Esquizofrenia: uma revisão. Psicologia Usp, 2016; (17 Sppl4): 1-10. https://doi.org/10.1590/s0103-

$\underline{65642006000400014}$

7. Silva RCB, Padovani RC, Neves MO. O delírio na perspectiva das neurociências e da terapia cognitiva. Brasileira de Terapias Cognitivas, 2011 Jun; (7 Sppl 7): 1-2.

8. Salum C; Pereira ACCl; Guimarães EABB. Dopamina, Óxido Nítrico e suas Interações em Modelos para o Estudo da Esquizofrenia. Universidade de São Paulo, 2008; 186-194.

9. Rainho JIM. Domínios da esquizofrenia e da perturbação delirante. Escola de Psicologia e Ciências da Vida, 2016; 1-133. https://doi.org/10.1590/S010279722008000200004

10. Santos AS. Custo-efetividade dos medicamentos antipsicóticos utilizados para o tratamento da esquizofrenia no Brasil. Ufmg 2016; 1-151.

11. Martinez MIV, León F, Torres F, Crossley NA. Antipsicóticos de primera y segunda generación en esquizofrenia: eficacia, efectividad y efecto de la dosis utilizada. Ars Medica, 2017 (42 Sppl 1): 41-48.

https://doi.org/10.11565/arsmed.v42i1.452 